\title{
Pharmaco-epistemology for the prescribing geriatrician
}

\author{
David G Le Couteur \\ Centre for Education and Research on Ageing, Concord RG Hospital \\ and the ANZAC Research Institute, Concord, New South Wales, and \\ the University of Sydney, Sydney, New South Wales, Australia
}

\section{Hal Kendig \\ Faculty of Health Sciences, University of Sydney, Sydney, New South Wales, Australia \\ Clinicians are becoming more reliant on their interpretation of clinical trial information to guide prescribing rather than their clinical skills. Thus to improve prescribing, it is increasingly important for clinicians to have an appreciation of epistemology (the science of knowledge and its interpretation) and the broader social context of knowledge. The insights of epistemologists can be useful in understanding the different ways in which clinical trials data are interpreted.}

Key words: epistemology, evidence-based medicine, geriatric medicine, pharmacology.

\section{Introduction}

It is not feasible for a clinician to have any personal experience or insight into whether many, if not most medications, have any efficacy or usefulness. Many medications are designed to reduce the risk of developing illness and it is almost impossible for a clinician to detect the absence of an illness [1]. Furthermore, the numbers needed to treat (NNT) for many medications are so large that no individual clinician has enough patients to be aware of any impact on outcomes (Table 1). In this setting, clinicians are unable to rely on their clinical judgement or pharmacological skills to guide their prescribing. Instead, evidence-based medicine (EBM) is now the judge of efficacy of medications. EBM holds the underlying assumptions that: (i) a drug is either effective or not effective; (ii) that well-performed clinical trials can determine whether the drug is effective or not effective; and (iii) that systematic analysis of multiple trials can provide even greater confidence about the efficacy of a medication [2].

This is a concrete and rational view of science and truth that excludes the possibility that there is a sociological context to knowledge and that the act of interpretation of data is dependent on prejudices, ideologies and preconceptions [2]. Most clinicians are rationalists or so-called logical positivists - like Dr Spock of Starship Enterprise, we believe that we determine the effectiveness and safety of medications in a rational, unprejudiced and unbiased fashion. However, in a study of

Correspondence to: Professor David G Le Couteur, Centre for Education and Research on Ageing, Concord RG Hospital. Email: dlecouteur@med.usyd.edu.au new drug prescribing in a British hospital it was found that only $17 \%$ of prescribing was driven by research evidence. Most prescribing was based on personal interactions with drug representatives and on what colleagues and key opinion leaders were saying and doing. It was concluded that doctors' 'knowledge is not objective and value-free, but socially and culturally determined' [3]. In a study of Australian doctors, information on new drugs came from communication with colleagues $(29 \%)$, pharmaceutical representatives $(18 \%)$ and hospital clinical meetings (15\%). Only a $13 \%$ of information came from journal articles [4]. Furthermore, the twin tenets of modern clinical trials - randomisation and blinding - do not have their foundations in any rational scientific or statistical prerequisites. These are mostly required to prevent the very human possibilities of fraud, lying and cheating. The statistical adjudicators of whether a drug is effective or not $(P<0.05$ or $95 \%$ confidence intervals (CI) not crossing unity) are little more than gambling criteria that can easily be manipulated through trial design and multiple comparisons [1,5]. These numbers certainly do not and cannot define the 'truth' about efficacy or cause and effect. Most publications that present positive research results based on $P<0.05$ are in fact negative [5].

How is it that exactly the same clinical trial data for dementia therapy were interpreted to have exactly the opposite meaning by the National Institute for Clinical Excellence compared with the pharmaceutical industry and various Alzheimer's associations in the UK [6]? (In fact, the high dropout rates from most of the cholinesterase inhibitor and memantine trials mean that drawing any conclusions is not possible [7].) Likewise exactly the same clinical trial data for streptokinase thrombolysis in acute stroke led to two opposing conclusions in two separate articles published by different members of the research team involved in the trial [8].

In younger patients where concerns about adverse drug reactions are of minor concern, it is may be reasonable to dismiss such concerns about interpretation as subversive and unhelpful. Instead, clinicians can practice 'socially valid' prescribing prescribing what everyone else is prescribing and what patients expect. In older people, adverse effects are much more common and more likely to lead to severe outcomes, death and hospitalisation $[9,10]$. We, as geriatricians, cannot afford to be so blasé in our interpretation of clinical trial data because of the increased likelihood of causing harm to our patients. Here we are simply applying the law of 'acceptable regret'; we are less likely to accept potentially false research findings when the adverse consequences of the research are high [11].

In order to prescribe in our patients' best interests, we should not only be expert in clinical medicine, pharmacology and 


\begin{tabular}{|c|c|c|c|}
\hline Pharmacotherapeutic intervention & Primary outcome & $\begin{array}{l}\text { Events over a 12-month } \\
\text { period per } 100 \text { patients } \\
\quad \text { with placebo }\end{array}$ & $\begin{array}{l}\text { Events over a 12-month } \\
\text { period per } 100 \text { patients } \\
\text { with intervention }\end{array}$ \\
\hline Anti-hypertensive therapy [33] & $\begin{array}{l}\text { Cardiovascular events and } \\
\text { death in older people }\end{array}$ & 3.5 & 2.5 \\
\hline Bisphosphonates [34] & Vertebral crush fracture & 5 & 3 \\
\hline Bisphosphonates [35] & Hip fracture & 0.66 & 0.33 \\
\hline Angiotensin converting enzyme inhibitors in heart failure [18] & Deaths & 13 & 11 \\
\hline Statins for secondary prevention [36] & Major coronary event & 5 & 4 \\
\hline Aspirin for secondary cardiovascular prevention [37] & Vascular events & 13 & 11 \\
\hline Warfarin in atrial fibrillation [38] & Strokes & 4 & 1.5 \\
\hline
\end{tabular}

evidence-based medicine, but should also have grounding in epistemology. Epistemology is the science of knowledge, the study of the nature, source, limits and validity of knowledge. Epistemologists are especially interested in developing criteria for evaluating claims that people make that they 'know' something. It underpins all science and often represents a discourse between external truths versus internal thinking, facts versus beliefs, mind versus material, and rationalism versus subjectivity. Few doctors know what epistemology is or means or have even considered the concept that knowledge may not be concrete and real.

Clinicians learn effectively from case studies. Thus, the following miscellany of epistemological 'case studies' are proposed to promote the value of a new science, that of 'pharmacoepistemology' - the application of epistemological ideas to the interpretation of clinical trials.

\section{Apply the Kierkegaard correction}

Soren Kierkegaard (1813-1855) was a Danish philosopher who in his attack on Hegel ('real is rational and rational is real') argued that 'subjectivity is truth'. In response to the scientific truths promulgated in the Enlightenment period, he marked the beginning of modernist philosophy where knowledge became viewed as less concrete and less externally valid than what rationalists would hope it might be [12]. In other words, observations depend on the views and interests of the observer as well as the nature of the phenomena being observed. Perhaps this is why the odds ratio for publishing positive results in randomised clinical trials is increased fourfold when the trial is funded by industry $[1,13]$. Of course it is not just the industry that benefits financially from a positive clinical trial - the benefits also flow to careers of academics whose research is funded on the basis of publications [1]. The pathogenesis of medical fraud and misrepresentation might lie in the so-called premed syndrome where $88 \%$ of medical undergraduates feel that cheating is acceptable for success. Furthermore, the 'publish or perish' pressure, where academic promotion and grant funding are linked to publications lead to a range of 'unfortunate' publishing practices $[14,15]$. When interpreting clinical trials, we should take into account the likely profitability of the result for the industry or academic before accepting the result as 'true'. The Bonferroni correction of the $P$-value is used to adjust the $P$-value for multiple comparisons. We suggest that the Kierkegaard correction be applied to correct the $P$-value for profitability: perhaps by dividing the published $P$-value of a positive trial by either (i) the millions of dollars in likely profit for the company or (ii) the number of publications that flows on for the academic.

\section{Discount the Derrida deconstruction}

Jacques Derrida (1930-2004) was a French philosopher who started the 'deconstructionist' movement. He argued that meaning comes from the act of interpretation of a text, not from the text itself, which is dead. Thus a text or work of literature that appeared to have one meaning could be interpreted to have an opposite meaning and this alternative interpretation could have more validity [12]. Deconstruction might explain why the conclusions of some clinical trials appear to be the opposite of the results. The authors' interpretation of the data can simply be considered more valid and more relevant than the data itself. For example, in a re-analysis of metoprolol in heart failure trials, it was found that in subjects older than 75 years, the relative risk of combined outcomes (hospitalisation and all cause mortality) was 0.79 (95\% CI $0.55-1.44$ ) and for total mortality was 0.71 (95\% CI $0.42-$ 1.19). According to accepted criteria the data indicate that metoprolol is ineffective in older people, yet the conclusion in this peer-reviewed article was that the time has come to overcome the barriers that physicians perceive to beta-blocker therapy and to provide it to the large number of elderly patients with heart failure' [16]. Likewise the SENIORS study found that the odds ratio for the primary outcome for people older than 75 years was $0.92(0.72-1.12)$, yet the conclusion was that nebivolol is 'an effective and well tolerated treatment for heart failure in the elderly' [17]. A meta-analysis of angiotensin-converting enzyme inhibitors in heart failure (level I evidence according to EBM terminology) found that in subjects older than 75 years, the odds ratio of death was 0.95 (0.74-1.22) and combined outcome (death/heart failure/ myocardial infarction) was 0.89 (0.69-1.13). Notwithstanding these statistically insignificant results, it was concluded that the results should be applied to all age groups [18] and elsewhere where 'beneficial effects have been observed in patients up to 95 years of age. Disappointingly only a proportion of elderly patients receive ACEI' [19]. When analysing clinical trial data, 
use both philosophical skepticism and methodological skills to recognise deconstruction - where the data from a clinical trial succumb to their subsequent interpretation by the authors.

\section{Popularise Popper}

Karl Popper (1902-1944) was a British philosopher who influenced scientific thought by promoting the idea that it is 'falsifiability' that distinguishes science from non-science, meaning that a hypothesis is only valid scientifically if it can be disproved. Thus negative results are very important. For example, it is difficult to prove that all swans are white, but the observation of a single black swan disproves the hypothesis [12]. This is seemingly incompatible with meta-analysis where many trials are combined to give an average result. Metaanalysis is the Popperian equivalent of saying that many white swans and one black swan means that all swans are light grey. Furthermore, what does it mean when 22 trials of betablockers in heart failure showed no effect on mortality and one trial showed a beneficial effect, yet the meta-analysis showed an overall beneficial effect [20]? Perhaps the most obvious failure to accept Popper occurs when a clinical trial that shows no efficacy was published, when most other trials have shown a positive effect. Often the negative trial is heavily criticised and then dismissed. For example many trials have shown the efficacy of cholinesterase inhibitors in Alzheimer's dementia. Yet the Alzheimer's disease 2000 study, which was not industryfunded, found that donepezil had no clinically relevant benefits [21]. The Lancet subsequently published numerous letters criticising the design and conclusions of this trial, for example 'numerous components of the methodology raise issues that limit the importance and generalisability of its findings to patients being considered for or currently treated with donepezil for mild-to-moderately-severe Alzheimer's disease. Difficulties include methods for patient selection, sample size, attrition rate, randomisation procedures, and the effects of multiple washout periods' [22]. Conversely, Popper would argue that we should take the results of such a negative trial very seriously.

\section{Invoke the inductive chicken}

Bertrand Russell (1872-1970) was a British philosopher who put forward the story of the inductive chicken as an argument against induction [12]. Induction is the process of extrapolating from the particular to the general. The tale is as follows: 'a farmer fattens a chicken for Christmas dinner by feeding it large amounts of food each morning. The chicken soon believes that each morning it will be fed so will live a long life. This induction is correct until Christmas eve when the chicken is decapitated'. In EBM, induction is equivalent to generalisability. Where it fails is when the clinical trial data obtained in typical clinical trial patients, usually middle-aged males, are applied to frail elderly patients. Spironolactone reduced mortality in clinical trial subjects with heart failure aged about 60 years. When this finding was extrapolated to the general population where most people with heart failure are older than 75 years, there was an increase in hyperkalaemic deaths and no change in heart failure hospitalisations [23]. COX2 inhibitors reduced gastrointestinal haemorrhages in clinical trial patients who were mostly younger, whereas usage was in the general population where most people with arthritis are elderly. This was associated with a $10 \%$ increase in hospital admissions for gastrointestinal haemorrhage [24]. The application of clinical trial data to frail older people is induction, and like Bertrand Russell's inductive chicken, may have negative outcomes [1].

\section{Play empiricist against rationalist}

The continental rationalist philosophers such as Rene Descartes (1596-1650) believed that knowledge could be deduced from an understanding of mechanisms and first principles. On the other hand, the British empiricists such as the physician Thomas Locke (1632-1704) believed that experimentation and observation gave knowledge: 'no mans knowledge here can go beyond his experience' [12]. Today this reflects the tension between the evidence and mechanism. Clinical trialists believe that a decision about whether a drug works or not can only be made empirically, that is with a clinical trial. The biologists on the other hand might argue that by understanding the mechanisms, one can predict the effect in patients. It is not unusual to see mechanism pitted against evidence and vice versa, in order to support a particular point of view. For example, COX2 inhibitors should reduce gastrointestinal haemorrhage on the basis of mechanisms and this concept was used to promote COX2 inhibitors despite the evidence from CLASS [25] and TARGET [26] studies that COX2 inhibitors have little if any effect. Likewise, the newer generation antidepressants and antipsychotic agents should cause less falls in older people on the basis of mechanisms (less anticholinergic effects and less extrapyramidal effects, respectively) and this was used to support their use in older people. The evidence, however, is that the rate of falls is similar between the newer and older agents $[27,28]$. Memantine is considered to be neuroprotective in dementia on the basis of mechanism (inhibition of neuroexcitatory amines) and this might encourage the use of this agent in demented subjects, yet there is no clinical trial evidence to support this [29]. It seems that if the evidence does not support one particular point of view then mechanisms might, and vice versa.

\section{Get Gettier}

Plato (428-348 вс) suggested that knowledge and certainty occurred when only something was Justifiable (provable or with reason), True (external validity) and Believed (internally accepted). This 'JTB' concept of knowledge held until the US philosopher, Edmund Gettier (1927-) provided simple examples that showed how this concept was flawed - the Gettier counter-examples [12]. An example could be: 'Elvis Presley is alive and hiding behind a very realistic Elvis Presley impersonator. An Elvis Presley fan, upon seeing the impersonator declares that Elvis Presley is alive'. All components of JTB are met, yet the fan is obviously mistaken. Similarly, we might feel reassured about our knowledge of the usefulness of medications, whenever we: (i) prescribe a medication, (ii) the patient gets improvement and (iii) the clinical trial was positive. This is an understandable JTB response that gives us confidence 
Table 2: The placebo effect. The effects of pharmacotherapeutic interventions on clinical outcomes in 100 subjects

\begin{tabular}{llcc}
\hline Pharmacotherapy & Disease or condition & $\begin{array}{l}\text { Number of subjects out of } \\
100 \text { that clinically improve }\end{array}$ & $\begin{array}{r}\text { Number of subjects out } \\
\text { of 100 that would have } \\
\text { improved with placebo }\end{array}$ \\
\hline Cholinesterase inhibitors [30] & Alzheimer's disease & 24 & 17 \\
Selective serotonin reuptake inhibitors [39] & Depression & 60 & 45 \\
Atypical antipsychotics [40] & Behavioural and psychological & 55 & 40 \\
Proton pump inhibitors [41] & symptoms of dementia & 89 & 83 \\
& Gastrointestinal haemorrhage & & \\
& (no re-bleeding) & & \\
\hline
\end{tabular}

about the efficacy of our prescribing. But in doing so, we are failing to see the Gettier Problem, because the response was most likely the placebo effect (the Gettier equivalent of the Elvis Presley impersonator). As shown from a few examples in Table 2, the majority of the benefit we perceive when we prescribe many medications would have occurred to subjects in the placebo arm of the trials. Of particular interest to geriatricians are the cholinesterase inhibitors in Alzheimer's disease. Here 24 of 100 subjects will have some perceptible improvement (e.g. improvement in CIBIC) and this is obviously very welcome and reassuring to us as clinicians. As scientists we should be aware of the Getter counter example - that 17 of these 24 subjects would have improved on placebo [30].

\section{Pick the prescribing pharmaco-meme}

Richard Dawkins (1941-) is a controversial British philosopher and scientist who put forward the concept of memes in his book The Selfish Gene (1976). He proposed that ideas and packets of information become accepted truths through communication and propagation (much like the evolution of genes). He called these ideas 'memes' and in some ways they are equivalent to urban myths, buzz marketing, propaganda and fads [31]. The Iraqi 'weapons of mass destruction' (WMD) are an example of a meme. Regardless of whether WMDs exist or not, there is no evidence for them yet many people are convinced that they exist and consider that to be a truth. The propagation of the idea of WMDs and their entrenchment as fact occurred as a result of communication. Much of our prescribing patterns are probably little more than memes prescribing fashions that are believed in the absence of evidence. For example in 2004 it was found that $85 \%$ of prescription by clinicians of valproate was for unproven and off-label indications such as manic-depressive psychosis, motor neurone disease, attention deficit hyperactivity disorder and withdrawal seizures. This usage had been promoted deliberately with key opinion leaders, ghost-writers, sales representative promotions, buzz marketing and Dorothy Dixers [32]. These sorts of pharmaco-memes (prescribing fashions) should be suspected each time a key opinion leader promotes a drug, or a discrepancy is noted between evidence and prescribing patterns.

\section{Conclusion}

We live in an information-rich environment and many of us are supermodernists, reliant on electronic sources for our knowledge. Because of large NNT and small benefits over placebo with many modern medications, we cannot rely on personal experience to guide our prescribing. We depend on information and evidence and in fact we prescribe information now rather than medications. An unquestioning acceptance of clinical trial data and evidence-based medicine makes us susceptible to many influences that might not be concordant with our patients' best interests. We need to realise that we are working in an environment of contestable knowledge, and that this perspective is necessary for understanding the moving and uncertain basis of the knowledge we use to guide our prescribing. By layering an understanding of some of these epistemological concepts beneath our understanding of EBM, we should be able to prescribe better to our older frail patients.

\section{Acknowledgements}

This is based on a talk given to the Australian and New Zealand Society for Geriatric Medicine, Christchurch, New Zealand (2006). The authors thank those members of the audience who requested that the talk be published. We also acknowledge the support of the Ageing and Alzheimer's Research Foundation (a division of the Medical Foundation of the University of Sydney).

\section{Key Points}

- An appreciation of the science of epistemology will serve geriatricians well when interpreting clinical trial data.

- Philosophers such as Kierkegaard, Derrida, Popper, Russell, Gettier and Dawkins provide insight into how data and scientific observations can be interpreted and misinterpreted.

\section{References}

1 Angell M. The Truth About Drug Companies. Melbourne, Vic.: Scribe, 2005.

2 Goldenberg MJ. On evidence and evidence-based medicine: Lessons from the philosophy of science. Social Science \& Medicine 2006; 62: 2621-2632.

3 Prosser $\mathrm{H}$, Walley T. New drug prescribing by hospital doctors: The nature and meaning of knowledge. Social Science \& Medicine 2006; 62: 1565-1578.

4 McGettigan P, Golden J, Fryer J, Chan R, Feely J. Prescribers prefer people: The sources of information used by doctors for prescribing suggest that the medium is more important than the message. British Journal of Clinical Pharmacology 2001; 51: 184-189. 
5 loannidis JP. Why most published research findings are false. PLOS Medicine 2005; 2: e124.

6 Dyer 0 . High court upholds NICE decision to limit treatments for Alzheimer's disease. British Medical Journal 2007; 335: 319.

7 Kaduszkiewicz H, Zimmermann T, Beck-Bornholdt HP, van den Bussche $\mathrm{H}$. Cholinesterase inhibitors for patients with Alzheimer's disease: Systematic review of randomised clinical trials. British Medical Journal 2005; 331: 321-327.

8 Horton R. MAST-I: Agreeing to disagree. Multicentre Acute Stroke Trial Italy Group. Lancet 1995; 346: 1504.

9 Hilmer SN, McLachlan A, Le Couteur DG. Clinical pharmacology in geriatric patients. Fundamental \& Clinical Pharmacology 2007; 21: 217-230.

10 Hilmer SN, Mager DE, Simonsick EM et al. A drug burden index to define the functional burden of medications in older people. Archives of International Medicine 2007; 167: 781-787.

11 Djulbegovic B, Hozo I. When should potentially false research findings be considered acceptable? PLoS Medicine 2007; 4: e26.

12 Copelston F. A History of Philosophy. New York: Image Books, 1985.

13 Lexchin J, Bero LA, Djulbegovic B, Clark O. Pharmaceutical industry sponsorship and research outcome and quality: Systematic review. British Medical Journal 2003; 326: 1167-1170.

14 Petersdorf RG. The pathogenesis of fraud in medical science. Annals of International Medicine 1986; 104: 252-254.

15 Woolf PK. Pressure to publish and fraud in science. Annals of International Medicine 1986; 104: 254-256.

16 Deedwania PC, Gottlieb S, Ghali JK, Waagstein F, Wikstrand JC. Efficacy, safety and tolerability of beta-adrenergic blockade with metoprolol CR/XL in elderly patients with heart failure. European Heart Journal 2004; 25 $1300-1309$

17 Flather MD, Shibata MC, Coats AJ et al. Randomized trial to determine the effect of nebivolol on mortality and cardiovascular hospital admission in elderly patients with heart failure (SENIORS). European Heart Journal 2005; 26: 215-225.

18 Flather MD, Yusuf S, Kober L et al. Long-term ACE-inhibitor therapy in patients with heart failure or left-ventricular dysfunction: A systematic overview of data from individual patients. ACE-Inhibitor Myocardial Infarction Collaborative Group. Lancet 2000; 355: 1575-1581.

19 Mangoni AA, Jackson SH. The implications of a growing evidence base for drug use in elderly patients Part 2. ACE inhibitors and angiotensin receptor blockers in heart failure and high cardiovascular risk patients. British Journal of Clinical Pharmacology 2006; 61: 502512.

20 Abdulla J, Kober L, Christensen E, Torp-Pedersen C. Effect of beta-blocker therapy on functional status in patients with heart failure - A meta-analysis. European Journal of Heart Failure 2006; 8: 522-531.

21 Courtney C, Farrell D, Gray R et al. Long-term donepezil treatment in 565 patients with Alzheimer's disease (AD2000): Randomised double-blind trial. Lancet 2004; 363: 2105-2115.

22 Akintade L, Zaiac M, leni JR, McRae T. AD2000: Design and conclusions. Lancet 2004; 364: 1214

23 Juurlink DN, Mamdani MM, Lee DS et al. Rates of hyperkalemia after publication of the Randomized Aldactone Evaluation Study. New England Journal of Medicine 2004; 351: 543-551.

24 Mamdani M, Juurlink DN, Kopp A, Naglie G, Austin PC, Laupacis A.
Gastrointestinal bleeding after the introduction of COX 2 inhibitors: Ecological study. British Medical Journal 2004; 328: 1415-1416.

25 Hrachovec JB, Mora M. Reporting of 6-month vs 12-month data in a clinical trial of celecoxib. Journal of the American Medical Association 2001; 286: 2398

26 Schnitzer TJ, Burmester GR, Mysler E et al. Comparison of lumiracoxib with naproxen and ibuprofen in the Therapeutic Arthritis Research and Gastrointestinal Event Trial (TARGET), reduction in ulcer complications: Randomised controlled trial. Lancet 2004; 364: 665-674

27 Hien LT, Cumming RG, Cameron ID et al. Atypical antipsychotic medications and risk of falls in residents of aged care facilities. Journal of the American Geriatrics Society 2005; 53: 1290-1295.

28 Thapa PB, Gideon P, Cost TW, Milam AB, Ray WA. Antidepressants and the risk of falls among nursing home residents. New England Journal of Medicine 1998; 339: 875-882.

29 Reisberg B, Doody R, Stoffler A, Schmitt F, Ferris S, Mobius HJ. Memantine in moderate-to-severe Alzheimer's disease. New England Journal of Medicine 2003; 348: 1333-1341.

30 Birks J. Cholinesterase inhibitors for Alzheimer's disease. Cochrane Database of Systematic Reviews 2006; (1): CD005593.

31 Dawkins R. The Selfish Gene. Oxford: Oxford University Press, 1976.

32 Steinman MA, Bero LA, Chren MM, Landefeld CS. Narrative review. The promotion of gabapentin: An analysis of internal industry documents. Annals of International Medicine 2006; 145: 284-293.

33 Mulrow C, Lau J, Cornell J, Brand M. Pharmacotherapy for hypertension in the elderly. Cochrane Database of Systematic Reviews 2000; (2): CD000028.

34 Dhesi JK, Allain TJ, Mangoni AA, Jackson SH. The implications of a growing evidence base for drug use in elderly patients. Part 4. Vitamin D and bisphosphonates for fractures and osteoporosis. British Journal of Clinical Pharmacology 2006; 61: 521-528.

35 Nguyen ND, Eisman JA, Nguyen TV. Anti-hip fracture efficacy of biophosphonates: A Bayesian analysis of clinical trials. Journal of Bone and Mineral Research 2006; 21: 340-349.

36 Costa J, Borges M, David C, Vaz Carneiro A. Efficacy of lipid lowering drug treatment for diabetic and non-diabetic patients: Meta-analysis of randomised controlled trials. British Medical Journal 2006; 332: 1115-1124.

37 Antithrombotic Triallists Collaboration. Collaborative meta-analysis of randomised trials of antiplatelet therapy for prevention of death, myocardial infarction, and stroke in high risk patients. British Medical Journal 2002; 324: 71-86.

38 Aguilar MI, Hart R. Oral anticoagulants for preventing stroke in patients with non-valvular atrial fibrillation and no previous history of stroke or transient ischemic attacks. Cochrane Database of Systematic Reviews 2005; (3): CD001927.

39 Arroll B, Macgillivray S, Ogston S et al. Efficacy and tolerability of tricyclic antidepressants and SSRls compared with placebo for treatment of depression in primary care: A meta-analysis. Annals of Family Medicine 2005; 3: 449-456.

40 Ballard C, Waite J. The effectiveness of atypical antipsychotics for the treatment of aggression and psychosis in Alzheimer's disease. Cochrane Database of Systematic Reviews 2006; (1): CD003476.

41 Leontiadis Gl, Sharma VK, Howden CW. Proton pump inhibitor treatment for acute peptic ulcer bleeding. Cochrane Database of Systematic Reviews 2006; (1): CD002094. 